\title{
Estimating Grassland Parameters from Sentinel-2: A Model Comparison Study
}

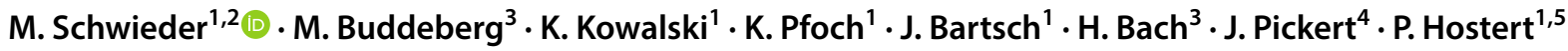

Received: 29 January 2020 / Accepted: 17 July 2020 / Published online: 5 August 2020

(c) The Author(s) 2020

\begin{abstract}
Grassland plays an important role in German agriculture. The interplay of ecological processes in grasslands secures important ecosystem functions and, thus, ultimately contributes to essential ecosystem services. To sustain, e.g., the provision of fodder or the filter function of soils, agricultural management needs to adapt to site-specific grassland characteristics. Spatially explicit information derived from remote sensing data has been proven instrumental for achieving this. In this study, we analyze the potential of Sentinel-2 data for deriving grassland-relevant parameters. We compare two well-established methods to calculate the aboveground biomass and leaf area index (LAI), first using a random forest regression and second using the soil-leaf-canopy (SLC) radiative transfer model. Field data were recorded on a grassland area in Brandenburg in August 2019, and were used to train the empirical model and to validate both models. Results confirm that both methods are suitable for mapping the spatial distribution of LAI and for quantifying aboveground biomass. Uncertainties generally increased with higher biomass and LAI values in the empirical model and varied on average by a relative RMSE of $11 \%$ for modeling of dry biomass and a relative RMSE of 23\% for LAI. Similar estimates were achieved using SLC with a relative RMSE of 30\% for LAI retrieval, and a relative RMSE of $47 \%$ for the estimation of dry biomass. Resulting maps from both approaches showed comprehensible spatial patterns of LAI and dry biomass distributions. Despite variations in the value ranges of both maps, the average estimates and spatial patterns of LAI and dry biomass were very similar. Based on the results of the two compared modeling approaches and the comparison to the validation data, we conclude that the relationship between Sentinel-2 spectra and grassland-relevant variables can be quantified to map their spatial distributions from space. Future research needs to investigate how similar approaches perform across different grassland types, seasons and grassland management regimes.
\end{abstract}

Keywords Grassland biomass $\cdot$ Soil-leaf-canopy radiative transfer model $\cdot$ Empirical model $\cdot$ Leaf area index $\cdot$ Sentinel-2

M. Schwieder

marcel.schwieder@geo.hu-berlin.de

1 Geography Department, Humboldt-Universität zu Berlin, Unter den Linden 6, 10099 Berlin, Germany

2 Thünen Institute of Farm Economics, Bundesallee 63, 38116 Brunswick, Germany

3 VISTA Remote Sensing in Geosciences GmbH, Gabelsbergerstraße 51, 80333 Munich, Germany

4 Leibniz Centre for Agricultural Landscape Research, Eberswalder Str. 84, 15374 Müncheberg, Germany

5 Integrative Research Institute on Transformations of Human-Environment Systems, IRI THESys, Humboldt-Universität zu Berlin, Unter den Linden 6, 10099 Berlin, Germany 


\section{Zusammenfassung}

Schätzung von Grünland-Parametern basierend auf Sentinel-2-Daten: Ein Vergleich von zwei Modellierungsansätzen. Grünland spielt eine wichtige Rolle in der deutschen Agrarlandschaft. Das Zusammenspiel ökologischer Prozesse unterstützt wichtige Ökosystemfunktionen und somit letztlich eine Reihe zentraler Ökosystemleistungen. Um diese gesellschaftlich relevanten Ökosystemleistungen wie z.B. die Bereitstellung von Futter oder die Filterfunktion der Böden zu erhalten, ist ein dem Grünlandstandort angepasstes Management entscheidend. Hierfür haben sich aus Fernerkundungsdaten abgeleitete räumlich explizite Informationen als sehr hilfreich erwiesen. In dieser Studie stellen wir die zwei methodischen Ansätze der empirischen Modellierung sowie des Strahlungstransfermodells soil-leaf-canopy (SLC) gegenüber, und beleuchten die Vor- und Nachteile beider Methoden für die Ableitung grünlandrelevanter Parameter aus Sentinel-2-Daten. Basierend auf Felddaten zu Biomasse und Blattflächenindex (LAI), die auf einer Grünlandfläche in Brandenburg im August 2019 aufgenommen wurden, konnten die Ansätze trainiert und validiert werden. Die Ergebnisse zeigen, dass beide Methoden die räumliche Verteilung des LAI sehr gut erfassen und die oberirdische Biomasse quantifizieren können. In der empirischen Modellierung nahmen die Unsicherheiten mit höheren LAI- und Biomassewerten zu und variierten im Durchschnitt um einen relativen RMSE von 11\% für die Modellierung von trockener Biomasse und einen relativen RMSE von 23\% für LAI. Ähnliche Ergebnisse wurden bei der Verwendung von SLC mit einem relativen RMSE von 30\% für die LAI-Modellierung und 47\% für die Schätzung der trockenen Biomasse erzielt. Die aus beiden Ansätzen resultierenden Karten zeigten übereinstimmende und realistische räumliche Muster von LAI- und Biomasseverteilungen. Trotz Abweichungen in den Wertebereichen beider Karten sind die durchschnittlichen Schätzungen von LAI und Biomasse sehr ähnlich. Die Ergebnisse beider Modellansätze und der Abgleich mit den erhobenen Validierungsdaten belegen, dass die Beziehung zwischen Sentinel-2-Spektren und grünlandrelevanten Variablen geeignet sind, deren räumliche Verteilung quantitativ abzubilden. Künftige Untersuchungen werden zeigen, welche Möglichkeiten und Grenzen beide Ansätze bei der Übertragung auf unterschiedliche Grünlandtypen, unterschiedliche Jahreszeiten und bei verschiedenem Flächenmanagement aufzeigen.

\section{Introduction}

Grasslands make up about $28.51 \%$ of the agricultural area in Germany (Destatis 2020) and are, thus, a characteristic landscape element. Depending on the respective management regime, these areas provide a wide range of ecosystem services that e.g., include carbon sequestration, water filtering, the provision of often species-rich habitats or the provision of fodder (Zhao et al. 2020; Blair et al. 2014; Sala and Paruelo 1997). The main economic use of grasslands is the production of dairy products and meat, by either herding livestock on pastures or mowing for fodder stocks (Smit et al. 2008). To sustain crucial ecosystem services in the context of a changing climate, while at the same time extracting sufficient amounts of nutrients to fulfill the demands on dairy products, appropriate management schemes are required. In Germany, grasslands are used both intensively and extensively and the management related to both systems requires information on optimal timing for management practices such as fertilization, harrowing, harvesting, or grazing periods. To optimize management decisions, remote sensing data have been proven to be instrumental for improved management decisions (Bastiaanssen et al. 2000; Schellberg et al. 2008; Schellberg and Verbruggen 2014), as information from space enables to gather management relevant data over large extents and in a frequent manner (Wachendorf et al. 2018; Bastiaanssen et al. 2000; Schellberg et al. 2008; Schellberg and Verbruggen 2014). An important parameter that can be derived from remote sensing is the leaf area index (LAI), which resembles the quantification of vegetation foliage per unit of ground area and is related to biosphere-atmosphere interactions such as photosynthesis and evapotranspiration (Chen and Cihlar 1996). The LAI allows insights into the state of vegetation, but also renders an important input variable for various modeling approaches, aiming to derive spatially explicit information on parameters that are relevant for grassland management such as soil moisture, yield estimates or fodder quality estimation (Herrmann et al. 2005; Löpmeier 1983; Nendel 2014).

Several studies have shown relations between spectral features in optical data and proxies of vegetation that relate e.g., to the percentage of grass cover, grassland biomass, or fodder quality (Gao 2006; Wang et al. 2019). These approaches are either based on empirical models that use spectral data combined with reference (field) data in a regression (e.g. Ali et al. 2014; Friedl et al. 1994; Obermeier et al. 2019) or sophisticated biophysical models, such as Radiative Transfer Models (RTM, e.g., Darvishzadeh et al. 2011; Quan et al. 2017). The latter are based on general formulized physical relationships between spectral properties and relevant variables that influence the scattering mechanisms in vegetation canopies (Verhoef 1998). RTMs model the transfer of radiation originating from the sun, its interaction with the earth's surface and its way back through the atmosphere to the satellite's sensor. Even though a fine spectral resolution of the input data is beneficial for both modeling approaches (Darvishzadeh et al. 2011, 2008; Obermeier et al. 2019), spaceborne hyperspectral data are not yet easily available, 
limiting studies to regional extents. Multi-spectral spaceborne data from the sensors onboard of the Sentinel-2A and B (S-2) satellites (Drusch et al. 2012), however, bear high potential for mapping grassland-relevant parameters (Delegido et al. 2011; Punalekar et al. 2018) at a spatial scale that suffices management demands (Ali et al. 2016).

The objective of this study is, thus, to analyze the potential of S-2 data for quantifying the leaf area index of grassland as well as the dry above ground biomass in managed temperate grasslands in Germany. We use S-2 data together with LAI and biomass reference data for a test site in Brandenburg in an empirical modeling approach as well as with the radiative transfer model soil-leaf-canopy (SLC), to answer the following research questions:

(i) Are the spectral and spatial resolutions of S-2 data sufficient to quantify and map the spatial distribution of LAI and above ground biomass on grasslands in Germany?

(ii) How do results from empirical modeling and SLC compare?

\section{Methods}

\subsection{Study Area}

Our study area is a managed grassland site located in the administrative district Havelland (Brandenburg) in northeastern Germany. In this administrative district, which is located in the North German Plain, grasslands represent a third of all agricultural land. This makes grassland an important land use in the area (Landkreis Havelland 2018). The study area has a size of approximately 43 ha (Fig. 1) and is a permanent grassland which is used for animal feed production. The study area is in the Havelländisches Luch, which is characterized by drained shallow fen soils with varying peat layer thickness and groundwater levels, causing moist or moderate moist sites within the fields. In the western half of the field, groundwater levels are somewhat higher compared to eastern parts. The canopy is dominated by grasses, mainly Lolium perenne L., Phalaris arundinacea L., Elymus repens L., Alopecurus pratensis L. and Festuca arundinacea Schreb.. Phalaris arundinacea and Festuca arundinacea which have a moisture index of 8 and 7 (Dierschke and Briemle 2008), and are very well adapted to the moist conditions on fen grassland. Under these conditions, the grasses can produce very high biomass with heights from 0.5 to $1.0 \mathrm{~m}$ when used for feed but can reach more than $1.5 \mathrm{~m}$ at older morphological stages. Furthermore, Phalaris arundinacea is an endemic grass species of Havelländisches Luch (common name: Havelmilitz), which was observed in similar sites to produce up to $5 \mathrm{t} \mathrm{DM/ha} \mathrm{dry} \mathrm{biomass}(\mathrm{BM})$ per cut at a LAI $>8$. The other grasses occur rather on the moderate moist parts of the site (moisture index 5-6). They are high yielding but of medium plant height with less than $0.5 \mathrm{~m}$ when young and up to $0.8-1 \mathrm{~m}$ at flowering. Herbs also appear in the canopy, though in lower proportion than grasses. The herbal plants present are Rumex ssp., species of Taraxacum and Ranunculus as well as of the legume Trifolium. The grass sward is usually mown three times per year, depending on the meteorological conditions during the growing season. The climate of the study region is characterized by continental conditions with warm summer temperatures and moderately cold winters. Based on the long-term average (1961-1990), the climate of the area is characterized by a temperature of $8.6^{\circ} \mathrm{C}$ and a precipitation of $521 \mathrm{~mm}$. Compared to the long-term average temperature of $13.6^{\circ} \mathrm{C}$ in the main vegetation season (April-October), the years 2018 and 2019 were very warm, as both had an average temperature of $16.7^{\circ} \mathrm{C}$. Additionally, the region suffered from drought during the years 2018 and 2019 (ZALF 2020). Although grasslands are more resilient to drought conditions than other crops, drought-related yield losses
Fig. 1 Study area in Brandenburg and the location of the field plots

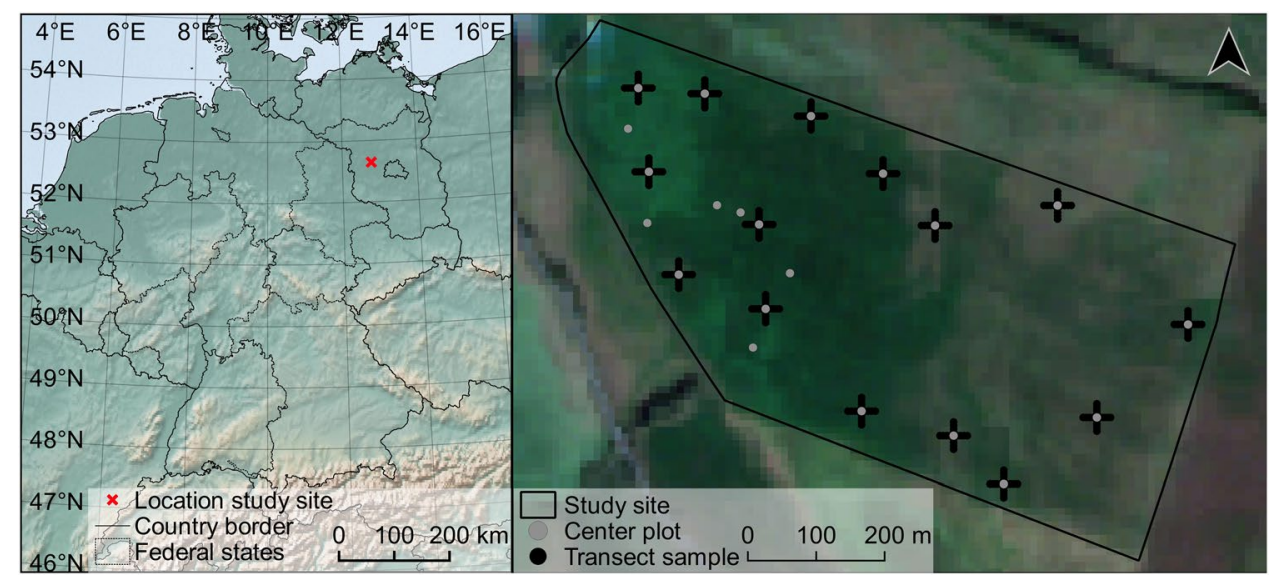


are expected to increase in the next decades with ongoing climatic changes across the region (Schindler et al. 2007).

\subsection{Field Measurements}

Field measurements were taken on the 9th of August 2019 approximately within $2 \mathrm{~h}$ before and after solar noon. The weather conditions were ideal with high solar radiation and few clouds. To capture the variability of vegetation within the field, we based our sampling design on a S-2 enhanced vegetation index (EVI) cluster map from the 28th of July 2019 with six classes of similar EVI values, which helped to identify appropriate sampling locations on site. Based on this map, 21 sample plots were selected as central measurement locations (Fig. 1). To capture the coordinates of the selected positions, we took GPS measurements with a Garmin Oregon device, and averaged the received signal over several minutes to minimize the positional error (Gao 2006). At the central plot, we took a white reference measurement using an Analytical Spectral Devices (ASD) FieldSpec 2 spectroradiometer that covers the spectral wavelength region from 450 to $2500 \mathrm{~nm}$ and subsequently a reflectance measurement of the vegetation (average of five measurements). We measured from a height of approximately $1.20 \mathrm{~m}$ leading, with an opening angle of $25^{\circ}$, to a ground sampling resolution of around $0.2 \mathrm{~m}^{2}$. Following the spectral measurement, we measured the compressed sward height (CSH) using a falling plate meter with a size of $0.46 \mathrm{~m} \times 0.46 \mathrm{~m}\left(0.2 \mathrm{~m}^{2}\right)$ following the instructions in Rayburn and Lozier (2003). We then cut the vegetation within the area of the falling plate meter approximately $5 \mathrm{~cm}$ above the ground, put the grasses in sampling bags with air holes and stored in cool box until processing in the laboratory. The fresh weight of the collected samples was measured in a laboratory before they were dried at $60{ }^{\circ} \mathrm{C}$ for $24 \mathrm{~h}$ in a convection oven after which the dry weight was measured. Around the central plot, we established an adapted star sampling design (Muir et al. 2011), with four 20-m transects in cardinal directions to cover a representative area surrounding each central plot, on each of which we took measurements on a transect point every $5 \mathrm{~m}$ (Fig. 2).

We obtained spectral reflectance measurements (using an ASD FieldSpec 3 spectroradiometer), CSH, and leaf area index (LAI) using the SS1 SunScan Canopy Analysis System, which measures the incoming light from the bottom of the canopy with 64 sensors within a lance of $1-m$ length. In parallel, the irradiance was measured using a hemispherical sensor on a tripod. Accordingly, we collected data at 17 locations per plot. Due to changing weather conditions, we could not use all measured spectra/LAI measurements at all transect points. Overall, we obtained 207 LAI measurements, 21 biomass samples, $229 \mathrm{CSH}$ measurements and 229 spectra (Fig. 3). Dry biomass (BM) values for each sampling point were estimated based on the $\mathrm{CSH}$ measurements using a linear regression (Fig. 3). The spectral measurements were used to simulate S-2 bands using the respective spectral response function (ESA 2017).

\subsection{Satellite Data}

For the model comparison, the S-2 scene was chosen which was recorded closest in time to the time of the LAI measurements. A cloudless scene was acquired by $\mathrm{S}-2$ on 28th of July 2019, 13 days before the field measurements were taken.

The scene was pre-processed using the Vista Imaging Analysis algorithm (VIA, Niggemann et al. 2014; Niggemann et al. 2015). Pre-processing within this processing chain includes an atmospheric correction, a land-use classification, masking of clouds and cloud shadows as well as detection and correction of cirrus clouds. Since the chosen scene was not covered by clouds or cirrus on the pixels within the area of interest no cloud masking or cirrus
Fig. 2 Field plot sampling design and measurements overview (left; details in the main text). Example of field spectral measurement and Sentinel-2 bandwidths (shaded) used in this study (right; blue (b), green $(\mathrm{g})$, red (r), three red-edge bands (re), near infrared (nir), shortwave infrared 1 (swir1), shortwave infrared 2 (swir2)
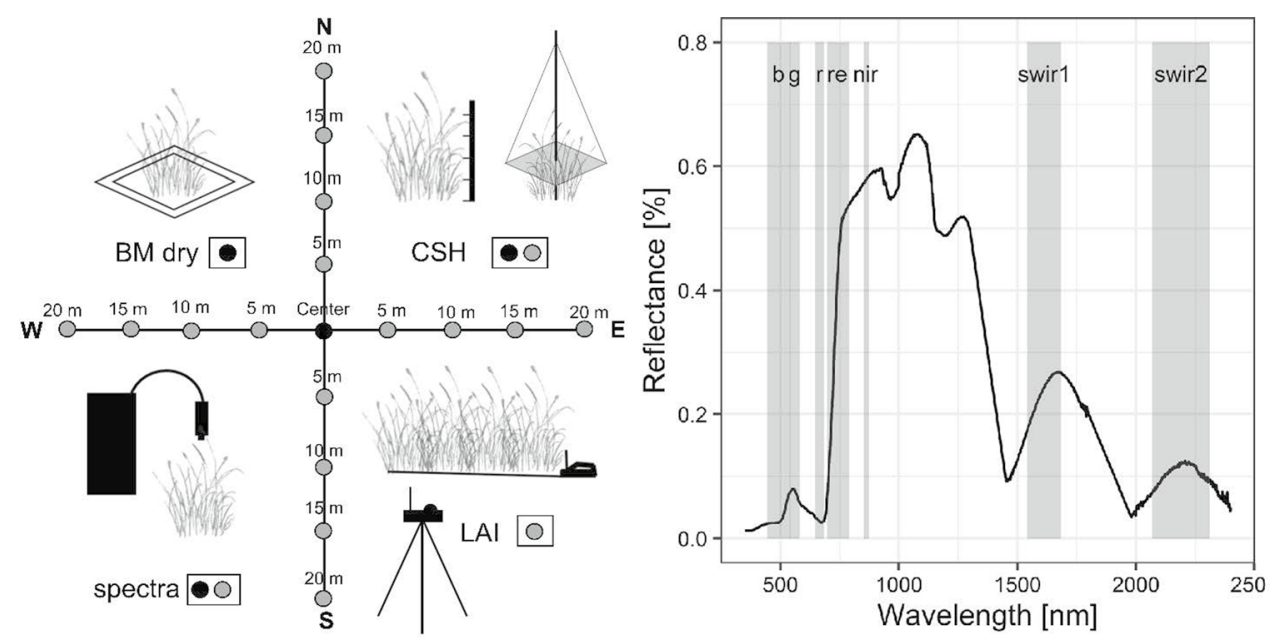

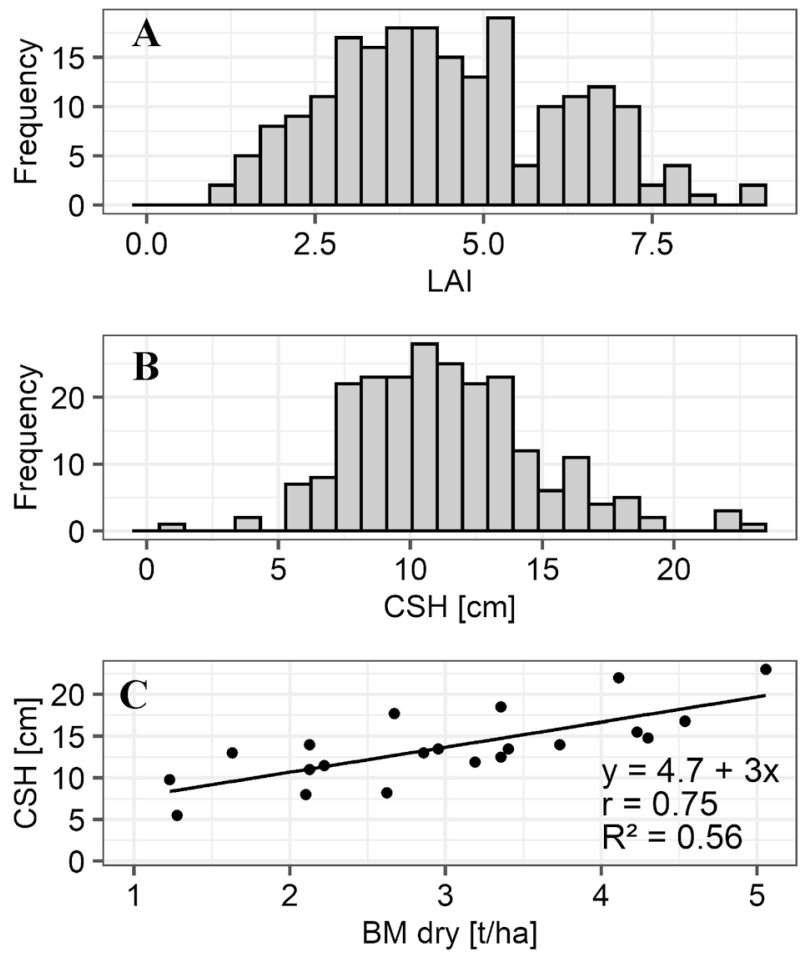

Fig. 3 Histograms of the LAI (a) and CSH (b) field measurements and a scatterplot (c) of the dry biomass values and the respective $\mathrm{CSH}$ measurements, which were used for modeling biomass values for each measurement point

correction was performed on the pixels within the test site. No Bidirectional Reflectance Distribution Function (BRDF) correction was performed within the VIA, since a BRDF correction is part of the radiative transfer modeling process within SLC. For the analysis, the $20-\mathrm{m}$ and $60-\mathrm{m}$ bands of the S-2 scene were resampled to $10-\mathrm{m}$ resolution. To reduce the effect that neighbouring pixels influence each other, an adjacency correction was applied. In this way, the influence of brightness differences of neighbouring pixels is reduced (Verhoef and Bach 2007; Bach 1995).

\subsection{Modeling Approaches}

We used a random forest regression to relate the simulated S-2 spectra with the LAI and biomass field measurements in an empirical model (EMP). Random Forests are an ensemble of individually trained decision trees aiming to average out modeling errors (Breiman 2001). To randomize the training of the decision trees they are grown with a subset of the input training data and only a pre-defined number of input predictors (mtry) is used at each decision tree node to find the optimal split. The empirical modeling was done in $\mathrm{R}(\mathrm{R}$ Core Team 2018) using the RandomForest package (Liaw and Wiener 2002) in which we set the number of trees to 500 and tuned the model parameters mtry using the tuneRF function. To get statistically robust results and an estimation of uncertainty, we iterated the modeling approaches for each of the variables (LAI and BM) 100 times with random splits of the input data using $70 \%$ of the data for model training and $30 \%$ of the data for model validation. Within each iteration model, performances were assed using the coefficient of determination $\left(R^{2}\right)$ and the root-mean-square error (RMSE). To make the performance metrics comparable between the two response variables, we normalized the RMSE (NRMSE) to the mean value of the respective set of validation data. The individual variable importance was assessed by calculating the increase in mean squared error (MSE) between the initial model and a model in which the variable to be assessed was permutated (Liaw and Wiener 2002).

As a second method to derive LAI estimates from the S-2 scene, the radiative transfer model SLC was used (Verhoef and Bach 2003, 2007). SLC is a physically based surface reflectance model that evolved from the GeoSAIL model (Verhoef and Bach 2003). Direct and diffuse fluxes of incident and reflected radiation are taken into account while modeling the radiation transfer in a so-called four-stream approach. Input variables for SLC are grouped into four different groups of variables including information about the satellite sensor, the observation geometry at the moment of satellite data acquisition, biophysical and biochemical properties of the vegetation canopy and the properties of the soil below the canopy. A two-layer modernized version of the model SAILH (Verhoef 1985) is used for canopy modeling in SLC; whereas, spectral reflectance and transmittance of green and brown leaves are calculated using the PROSPECT sub-model (Jacquemoud and Baret 1990). To account for soil reflectance characteristics a non-Lambertian soil BRDF sub-model for soil reflectance and its variation with moisture is incorporated in SLC (Verhoef and Bach 2007). SLC models potential reflectance spectra by varying the input parameters. For this study, a look-up-table approach was used to calculate all possible solutions resulting of the variation of the inverted parameters. The parameter combination that best describes the conditions of earth's surface is chosen by comparing modeled and measured reflectance spectra and choosing the result with the lowest RMSE. The soil input dataset was adapted to resemble the soil characteristics of the study site by measuring reference spectra on adjacent arable fields during a moment when the bare soil was visible and converting the derived S-2-spectra into single scattering albedo values to use as soil-background layer for the model calculations in SLC (Verhoef and Bach 2007). By doing this, the influence of the reflectance characteristics of the soil, that can influence the reflectance spectra of a site when the soil is not entirely covered by vegetation, can be taken into account. Green leaf area, leaf chlorophyll content and the leaf angle distribution within the canopy were inverted. Dry biomass values for each pixel were calculated by multiplying 
the inverted green leaf area with the leaf mass per area (LMA). Leaf mass per area is a species-specific parameter that also varies with the phenological stage of the plants and with LAI. For this study, the LMA value was calculated from the field data by calculating the ratio between dry biomass values and the measured leaf area for each sample site and averaging the values. The site-specific LMA was then applied to calculate the dry biomass values from the inverted green leaf area. Model performance of SLC is evaluated by comparing modeled to input spectra, where input spectra refer to the surface reflectance measured by S-2.

\subsection{Validation}

To assess the model accuracy, the calculated values were compared to the reference data collected in the field. This was done separately for both modeled parameters LAI and

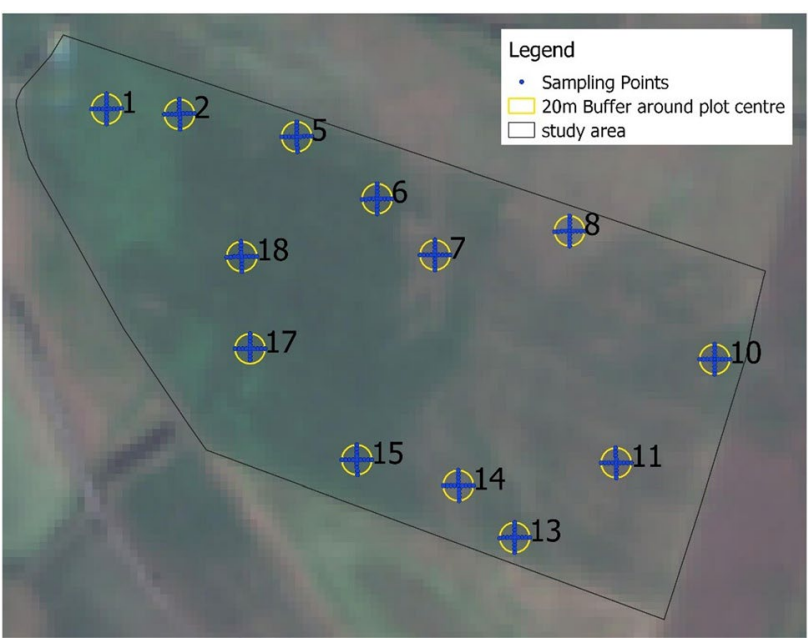

Fig. 4 Location of the transects and field sampling points within the study area. The 20-m buffer around the central plot coordinates were used for averaging LAI and BM model estimations, which were subsequently used for validation
BM. Once the LAI values from sample locations with varying lighting conditions had been excluded, a total of $207 \mathrm{LAI}$ and $228 \mathrm{BM}$ (calibrated using CSH) measurements could be used for validation. Based on the transect sampling design, we matched the point measurements of LAI and BM to the estimated pixel values from the SLC and the EMP. CSH and LAI measurements were taken on the 20-m transect lines with a distance of $5 \mathrm{~m}$ between each sample point (Fig. 2). This means that often more than one sample point lies within a pixel of the S-2 scene. Therefore, we averaged all values per plot and compared the mean value for each plot with the averaged modeled pixel values located within a $20-\mathrm{m}$ buffer around the central coordinate of the plot. For this validation, only the 13 plots were used, at which all point measurements were valid (Fig. 4). In this way, we accounted for geometric inaccuracies which might be due to GPS positioning errors and the positional accuracy of the S-2 image.

\section{Results}

\subsection{Empirical Models}

Based on the randomly sampled sets of training and validation data during each of the 100 model iterations, we were able to derive robust model performance measures for the estimation of LAI and biomass. BM was estimated with a mean $R^{2}$ of $52 \%$ (44-66\%) and an NRMSE of $17 \%$ (14-22\%). LAI models performed with a mean $R^{2}$ of 0.62 (0.44-0.81) and an NRMSE of 23\% (19-28\%; Fig. 5).

The comparison between the values of the LAI and the BM map showed comparable spatial patterns and a strong correlation with a Pearson-correlation coefficient of 0.98 , with higher deviations at low and high ends of the data ranges (Figs. 5, 6). The related standard deviations also revealed similar spatial patterns, with higher deviations from the mean with increasing LAI and BM values (Fig. 6). Both maps indicated higher LAI and BM values on the western
Fig. 5 Distribution of the internal model performance measures $R^{2}$ (a), relative RMSE (b) for LAI and BM models after 100 iterations. Scatterplot of LAI and BM mean estimates for the whole study area after 100 iterations with Pearson correlation coefficient $r$ (c)
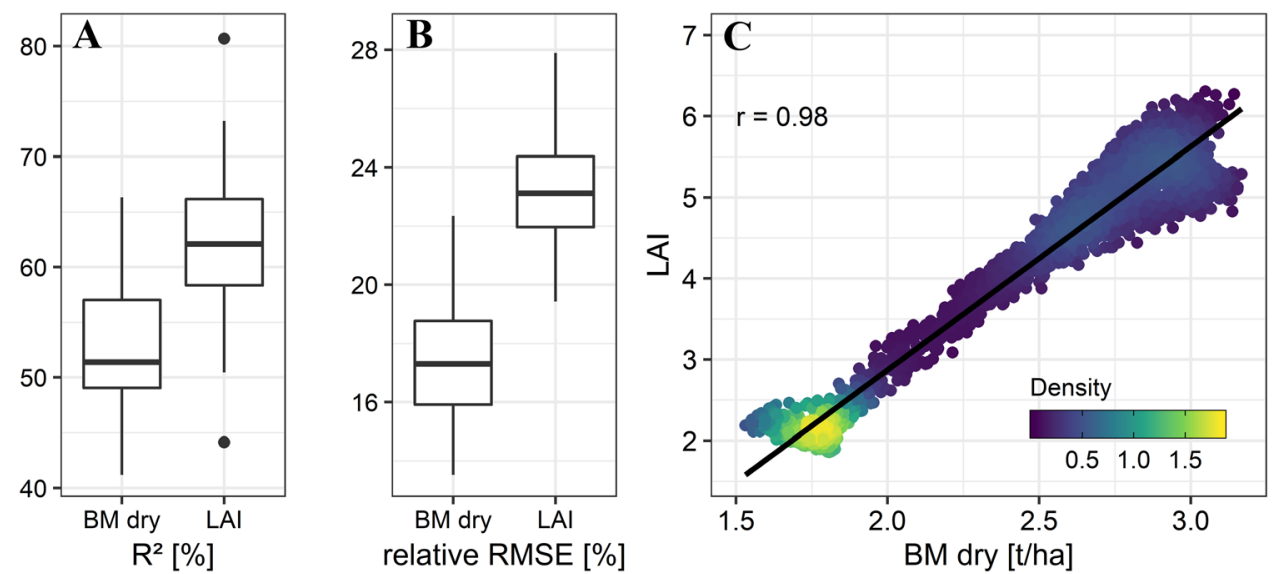
half of the field in the moist part and lower values of both variables in the eastern half in the moderate moist part, along with smaller local variations in both sides of the field. This resulted in an overall mean LAI of 3.5 and an overall mean BM of $2.2 \mathrm{t} / \mathrm{ha}$. The comparison with the field data resulted in a $R^{2}$ of $79 \%$ and a NRMSE of $23 \%$ for the LAI. Agreement between the field data and the mapped BM was assessed with an $R^{2}$ of $90 \%$ and a NRMSE of $11 \%$ (Fig. 9).

For both variables, we observed a similar ranking in variable importance. On average, the most influential predictor variable for estimating LAI and BM was the Rededge-NIR band (central wavelength $(\mathrm{CW}): 779.7 \mathrm{~nm}$ ), followed by the bands NIR (CW: $864 \mathrm{~nm})$ and red (CW: $664.9 \mathrm{~nm})$ for LAI

Table 1 Mean random forest variable importance after 100 iterations for BM and LAI estimation

\begin{tabular}{lll}
\hline & $\begin{array}{l}\text { Mean increase MSE LAI } \\
{[\%]}\end{array}$ & $\begin{array}{l}\text { Mean increase } \\
\text { MSE BM [\%] }\end{array}$ \\
\hline Blue & 13.70 & 10.21 \\
Green & 10.91 & 11.06 \\
Red & 15.77 & 15.35 \\
RE1 & 10.31 & 9.99 \\
RE2 & 13.34 & 15.19 \\
RENIR & 17.69 & 17.74 \\
NIR & 16.76 & 15.12 \\
SWIR1 & 9.27 & 13.98 \\
SWIR2 & 9.84 & 12.69 \\
\hline
\end{tabular}

prediction; and red and Redegde-2 (CW: $739.1 \mathrm{~nm})$ in the BM models (Table 1).

\subsection{Radiative Transfer Models}

Comparison of reflectance spectra modeled by SLC to reflectance spectra measured by S-2 across all pixels of the test site result in an average RMSE of 1.57, indicating an overall good model fit. Spatial analysis of the RMSE shows an even distribution over the entire test site (Fig. 7), which indicates that the allowed variation of parameters used for model inversion provides robust modeling without clustering of residuals. The eastern part of the study site shows smaller LAI and BM values in comparison to the western half, with some smaller areas with the highest values (LAI of 7; BM of $5 \mathrm{t} / \mathrm{ha}$ ). The mean modeled green LAI over all validation plots for the satellite scene acquired on 28th of July 2019 was 4.02 , in comparison to a mean measured LAI of 4.48 derived from field measurements in 9th of August 2019. Comparison of the modeled LAI values to the validation data results in an $R^{2}$ of $78 \%$ and a NRMSE of $30 \%$. The biomass prediction was evaluated with an overall $R^{2}$ of $90 \%$ and NRMSE of $47 \%$ (Fig. 9).

\subsection{Model Comparison}

Visual comparison of the results revealed similar spatial patterns modeled by both approaches, both for LAI as well as for biomass estimation. The mean values for the
Fig. 6 LAI and BM estimates (a, c) and related standard deviation (STD; b, d) based on 100 model iterations
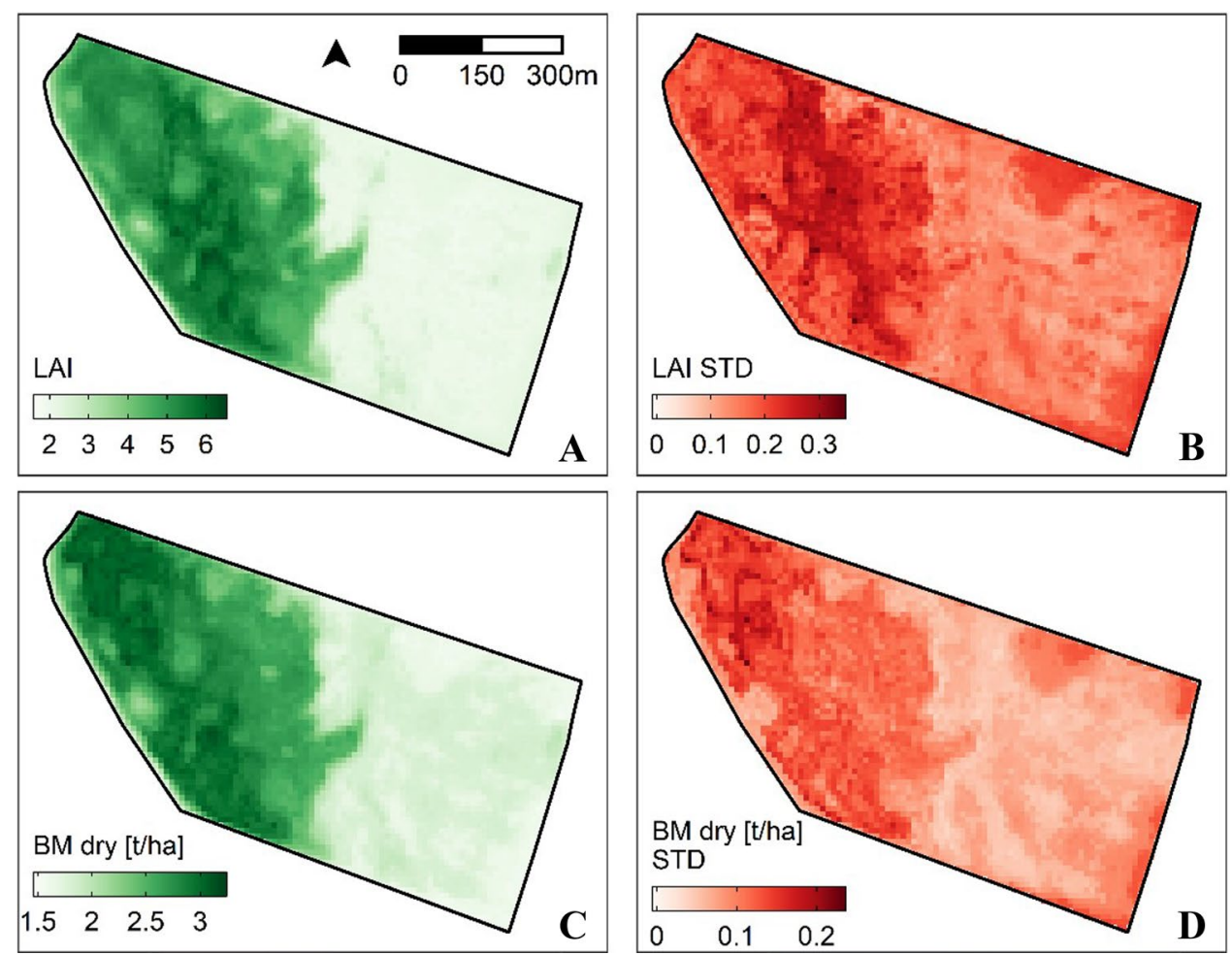
entire field were very similar with a mean LAI (SLC) of 3.61 compared to LAI (EMP) of 3.51 and average BM values of $2.49 \mathrm{t} / \mathrm{ha}$ (SLC) and $2.23 \mathrm{t} / \mathrm{ha}$ (EMP). In both maps, the western half of the study site was dominated by higher LAI and BM values; whereas, the eastern part of the field had lower values (Figs. 6, 7). The highest differences between both maps were found at the extreme ends of the data range with empirical model results being higher than the SLC results in the lower value ranges and lower values at the high end of the data range (Fig. 8). Direct comparison of model results to each other for every modeled pixel within the study site resulted in a very high correlation for LAI $(r=0.95)$ and BM $(r=0.96)$. In comparison to the results of the radiative transfer model, where modeled LAI values varied between 0.68 and 9, the results of the empirical model showed slightly less variation, with modeled values for LAI which varied between 1.86 and 6.31. The comparison of the plot-wise averaged modeling results (within a $20-\mathrm{m}$ buffer) to the field data (mean values per plot), showed good relations (in terms of $R^{2}$ values) for the SLC as well as for the EMP models (Fig. 9). The per plot-averaged LAI field values range from 1.78 to 6.91 , while the SLC results range from 0.86 to 8.14, and the EMP values from 2.07 to 6.09. Mean BM field measurements range from 1.77 to $3.53 \mathrm{t} / \mathrm{ha}$, SLC BM estimates from 0.59 to $5.62 \mathrm{t} / \mathrm{ha}$ and EMP BM values from 1.59 to $3.07 \mathrm{t} / \mathrm{ha}$. These differences are quantified in the respective NRMSE values. In general, it can be observed
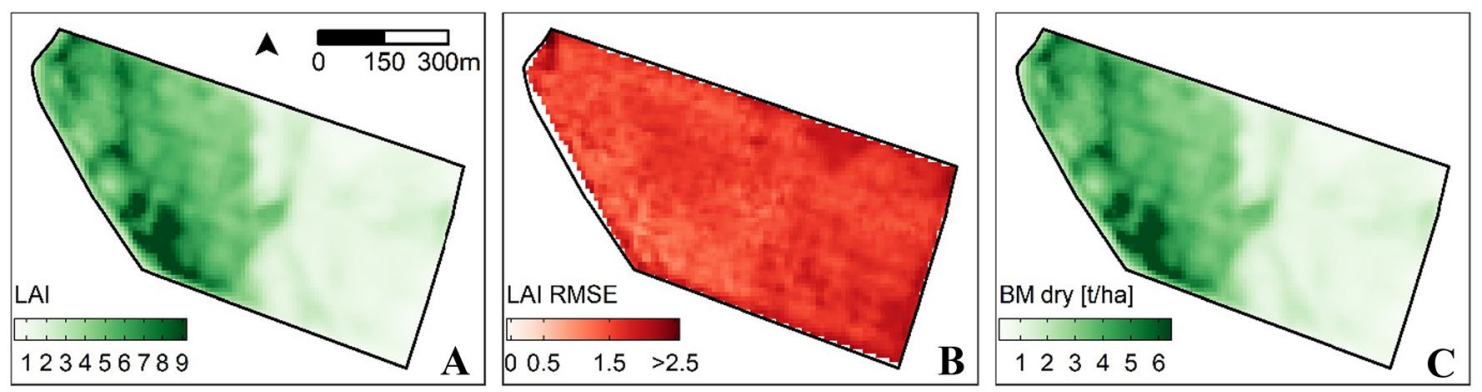

Fig. 7 SLC LAI estimates with related RMSE (a, b) and biomass estimates (c)

Fig. 8 Difference maps (A, C) and scatterplots $(\mathbf{B}, \mathbf{D})$ of LAI and BM resulting from the empirical model and the RTM
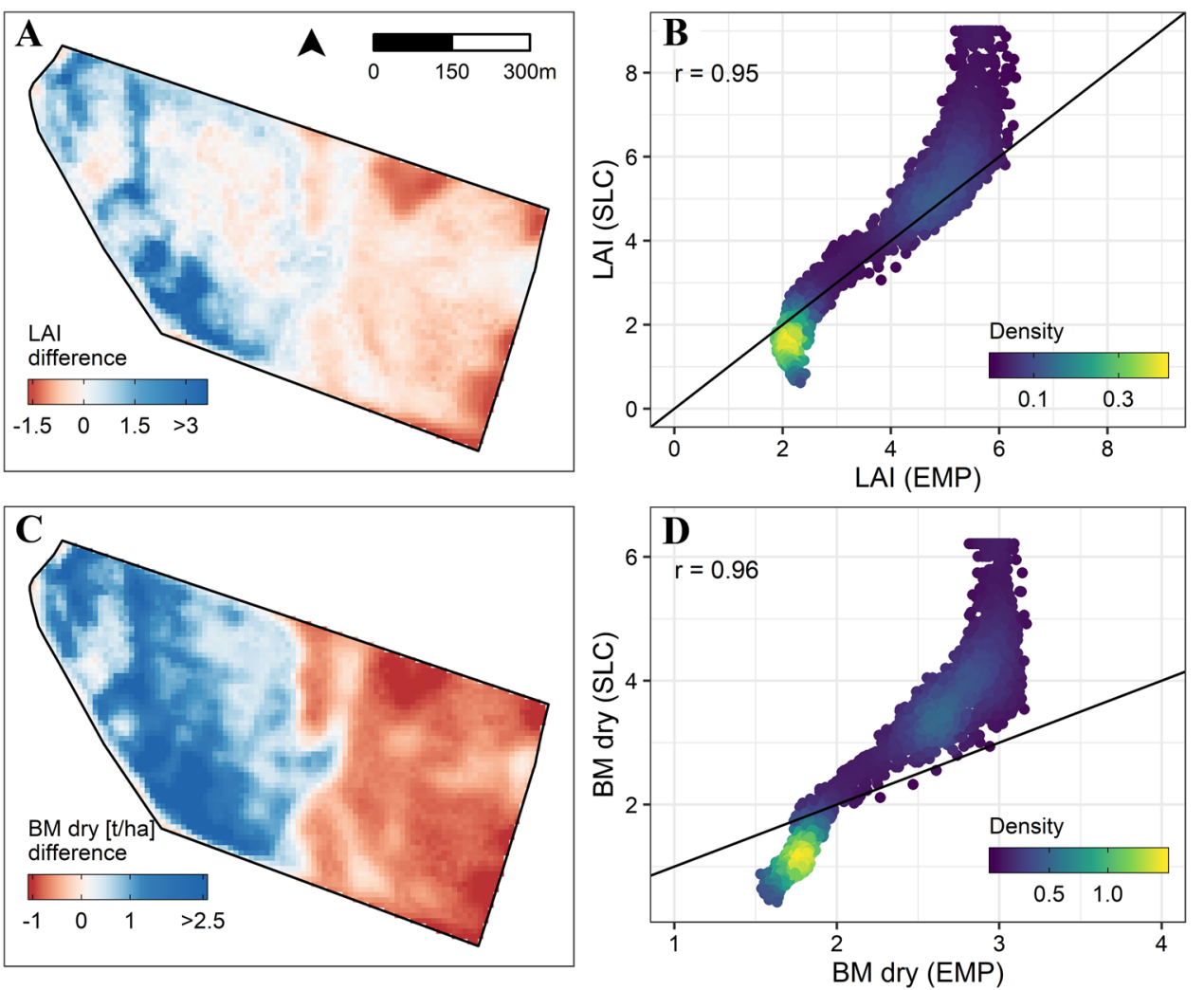
Fig. 9 Comparison of average ( \pm 1 standard deviation) LAI (upper row) and BM (lower row) values for each transect measured in the field to the SLC and empirical model outputs averaged within a 20 - $\mathrm{m}$ buffer around the central coordinate
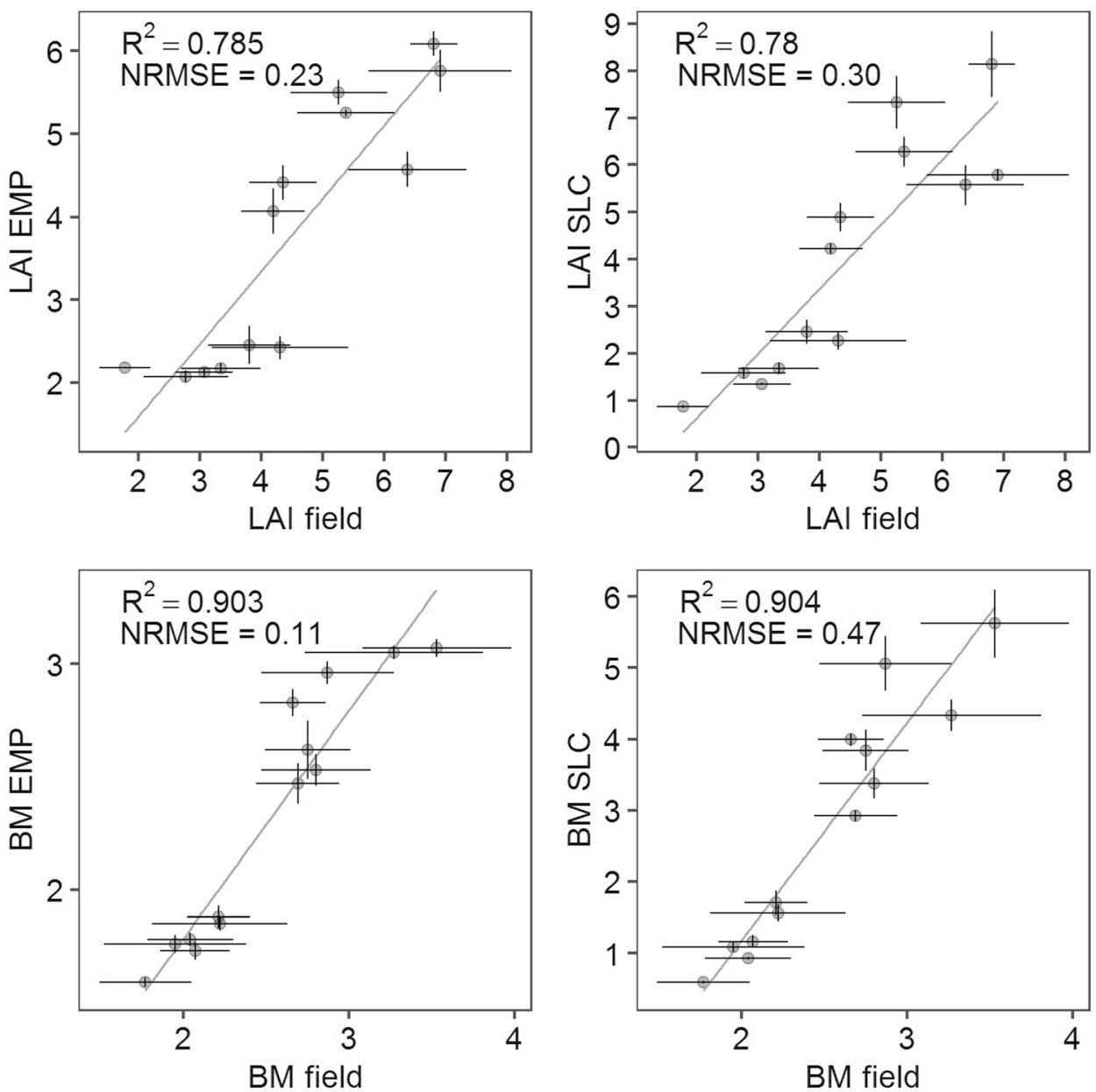

that the plot-wise standard deviation is higher in the field values, in comparison to both model estimations of LAI and BM (Fig. 9).

\section{Discussion}

We were able to quantify and map the spatial distribution of LAI and above-ground dry biomass with two modeling approaches on a grassland site in Brandenburg from field reference data and S-2 spectra. The results corroborate that the spectral characteristics of S-2 data enable to derive grassland parameters with a spatial resolution of $10 \mathrm{~m}$ that allows to adjust local management schemes. As expected, the spectral bands of the red and near-infrared regions of the electromagnetic spectrum were the most influential in the empirical model. This confirms findings of other studies (Darvishzadeh et al. 2009, 2019; Punalekar et al. 2018); whereas in our study, especially the Rededge-NIR band with a central wavelength of $783 \mathrm{~nm}$ and a bandwidth of $20 \mathrm{~nm}$ (Drusch et al. 2012) was ranked as most important for the estimation of LAI and BM, while the SWIR bands were less important.
The spatial patterns in the resulting maps of the SLC and the empirical model are highly correlated and the comparison of the results from both modeling approaches led to comprehensible spatial patterns of LAI and BM. In all four maps from the two modeling approaches, the western half of the observed field was characterized by higher values, in comparison to the eastern half. This is particularly due to Phalaris arundinacea that reaches higher portions in the swards under moist site conditions and occurs mostly in the western part. The variation of measured and modeled values for LAI and BM is very high on the plot level. This is probably due to the high heterogeneity of species composition in the stand.

In general, the model performance metrics as well as the ones derived from the comparison of field reference data with the model outcomes suggest that both variables, LAI and BM, could be modeled with similar accuracies, although the predicted data range in the SLC model is somewhat higher. Still both models led to LAI predictions in a range that is comparable to values that were modeled for other grassland sites in Germany (e.g., Asam et al. 2015). Modeling errors might partly be due to the spatial heterogeneity of 
the species distribution within the observed grassland. The grassland canopy in the study site is very heterogeneous, with areas of varying species composition that may have led to LAI hotspots with comparably high values especially in the SLC results. These species differ, e.g., in their chlorophyll content and leaf angle, which are both inverted variables for the SLC model, in which not all possible variable combinations that were present on the grassland site might have been included in the initial model. Similar observations were reported in Darvishzadeh et al. (2008) where radiative transfer LAI model performances increased when considering only plots with two species. Here, additional information on expected species composition could be helpful to fine-tune the model accordingly. For the empirical modeling approach, a high species heterogeneity is also challenging, as it requires a high number of representative field samples covering variations in LAI (and BM) but also species composition. Here, LAI was measured in the field using a predefined leaf angle, which was not adjusted for individual species. Furthermore, no LAI below one was measured in the field, which explains the discrepancy in the lower values of the SLC and empirical model results.

Concerning the estimation of BM, the empirical model in this study led to better model performances as it was directly trained with the entire range of BM across the study site. However, the final map with mean BM values of 100 model iterations did not cover the extreme values of the field samples. This might be due to the empirical random forest modeling approach which is based on subsets of field data and may not always include data from the few extreme values. Moreover, the calibration of the falling plate meter measurements with the 21 dry BM weights showed moderate correlation, which propagates to the final model and explains model uncertainty. This could be improved using more calibration samples. Nonetheless, the high correlation between the LAI and BM values resulting from the empirical model from independent data collections suggests that the field data are reliable and the estimated values realistic. For the SLC, the time lag of 13 days between field data collection and the acquisition date of the S-2 image might have impacted the accuracy of the results since the LMA, that was derived from the field measurement data, might have changed in the period between the acquisition of the satellite scene and the field sampling. Variations of LMA within time can be accounted for by assimilating derived LAI values into a plant growth model and calculating the biomass within the model (Hank et al. 2012, 2015). Due to a lack of precise information, we here assumed an average LMA for the entire study site based on field data. Supporting the importance of species-specific input parameters, Punalekar et al. (2018) found that biomass estimates from a radiative transfer model were more accurate for grassland sites with homogenous species composition compared to mixed-species fields.
Overall, BM estimations of the two models agree well with the actual reported yield. The analyzed area was harvested on 10th of August (1 day after the field measurements were taken) with an average BM yield of $1.9 \mathrm{t} / \mathrm{ha}$. In comparison, we estimated average BM values of $2.49 \mathrm{t} / \mathrm{ha}$ with the SLC model and 2.23 t/ha with the empirical model, which underlines the reliability of the modeling results. The mean BM estimates are in a reliable range when compared to reported average grassland yields in Havelland for the period 2010-2015, with a mean annual yield (after several cuts) of 5.34 t/ha (AfS Berlin-Brandenburg 2017). Despite severe drought in 2018 and temperatures above the average in 2019, the measured and modeled BM is within the expected range for a summer cut on a moist/moderate moist fen grassland.

\section{Conclusion}

Based on the results of the two compared modeling approaches, we conclude that the relationship between S-2 spectra and grassland-relevant variables was suitable to map their spatial distribution. We were able to map LAI and dry $\mathrm{BM}$ with comprehensible spatial patterns and meaningful overall estimates of the observed values for the test site in Brandenburg. The modeled dry biomass from the two compared approaches was well in line with the actual reported yield. Under similar conditions, which can for example be found in large parts of northern Germany, the established models will likely perform similar. However, future studies shall model the transferability of our results, specifically concerning different environmental conditions such as soil type, water availability, species composition, as well as different management regimes. Our results showed high correlations between the outcomes of SLC and empirical modeling, even though both approaches were trained and parameterized independently. Highest differences between the two approaches were observed at the low and far end of the data range, which highlights the importance of a representative distribution of training data for the empirical model and an optimized parametrization of the SLC for modeling LAI and BM for heterogeneous grasslands. Follow-up studies should, thus, investigate how the combination of SLC with sophisticated plant growth models influences the results, and if this combination enables model generalization.

Acknowledgements Open Access funding provided by Projekt DEAL. This study was conducted within the framework of the collaborative research project SattGrün funded by the Federal Ministry of Food and Agriculture (BMEL; Project No. 331231 0110). The authors would like to thank our associated Partner Peter Kaim for allowing field measurements at the Havellandhof Ribbeck. We further thank all the people who supported the field sampling: Sam Cooper, Andrey Dara, David Frantz, Thanh-Hien Huynh, Johannes Isensee, Bahareh Kamali, Viet 
Hoang Nguyen and Pablo Rosso, as well as Kerstin Deetz and Dagmar Wacker for preparing and weighting the field samples in the laboratory.

Data Availability The R code that was used for the empirical modeling approach is available on Github and can be accessed from https://githu b.com/geo-masc/GLmodel. The data sets used in this study are not publicly available, but we encourage researchers that are interested in collaborations to contact us.

Open Access This article is licensed under a Creative Commons Attribution 4.0 International License, which permits use, sharing, adaptation, distribution and reproduction in any medium or format, as long as you give appropriate credit to the original author(s) and the source, provide a link to the Creative Commons licence, and indicate if changes were made. The images or other third party material in this article are included in the article's Creative Commons licence, unless indicated otherwise in a credit line to the material. If material is not included in the article's Creative Commons licence and your intended use is not permitted by statutory regulation or exceeds the permitted use, you will need to obtain permission directly from the copyright holder. To view a copy of this licence, visit http://creativecommons.org/licenses/by/4.0/.

\section{References}

Ali I, Cawkwell F, Green S, Dwyer N (2014) Application of statistical and machine learning models for grassland yield estimation based on a hypertemporal satellite remote sensing time series. In: 2014 IEEE geoscience and remote sensing symposium, 13-18 July 2014. pp 5060-5063. https://doi.org/10.1109/IGARS S.2014.6947634

Ali I, Cawkwell F, Dwyer E, Barrett B, Green S (2016) Satellite remote sensing of grasslands: from observation to management. J Plant Ecol 9:649-671. https://doi.org/10.1093/jpe/rtw005

Asam S, Klein D, Dech S (2015) Estimation of grassland use intensities based on high spatial resolution LAI time series. Int Arch Photogramm Remote Sens Spat Inf Sci 40:285-291. https://doi. org/10.5194/isprsarchives-XL-7-W3-285-2015

Bach H (1995) Die Bestimmung hydrologischer und landwirtschaftlicher Oberflächenparameter aus hyperspektralen Fernerkundungsdaten. München

Bastiaanssen WGM, Molden DJ, Makin IW (2000) Remote sensing for irrigated agriculture: examples from research and possible applications. Agric Water Manag 46:137-155. https://doi.org/10.1016/ S0378-3774(00)00080-9

Berlin-Brandenburg AfS (2017) Ernteberichterstattung über Feldfrüchte und Grünland im Land Brandenburg 2016. Potsdam, Germany

Blair J, Nippert J, Briggs J (2014) Grassland ecology. In: Monson RK (ed) Ecology and the environment. Springer, New York, pp 389423. https://doi.org/10.1007/978-1-4614-7501-9_14

Breiman L (2001) Random forests. Mach Learn 45:5-32. https://doi. org/10.1023/A:1010933404324

Chen JM, Cihlar J (1996) Retrieving leaf area index of boreal conifer forests using Landsat TM images. Remote Sens Environ 55:153-162

Darvishzadeh R, Skidmore A, Schlerf M, Atzberger C, Corsi F, Cho M (2008) LAI and chlorophyll estimation for a heterogeneous grassland using hyperspectral measurements. ISPRS J Photogramm Remote Sens 63:409-426. https://doi.org/10.1016/j.isprs jprs.2008.01.001

Darvishzadeh R, Atzberger C, Skidmore AK, Abkar AA (2009) Leaf area index derivation from hyperspectral vegetation indices and the red edge position. Int J Remote Sens 30:6199-6218. https:// doi.org/10.1080/01431160902842342

Darvishzadeh R, Atzberger C, Skidmore A, Schlerf M (2011) Mapping grassland leaf area index with airborne hyperspectral imagery: a comparison study of statistical approaches and inversion of radiative transfer models. ISPRS J Photogramm Remote Sens 66:894906. https://doi.org/10.1016/j.isprsjprs.2011.09.013

Darvishzadeh R et al (2019) Analysis of Sentinel-2 and RapidEye for retrieval of leaf area index in a saltmarsh using a radiative transfer model. Remote Sens 11:671

Delegido J, Verrelst J, Alonso L, Moreno J (2011) Evaluation of Sentinel-2 red-edge bands for empirical estimation of green lai and chlorophyll content. Sensors 11:7063-7081

Destatis (2020) Statistisches bundesamt. Wiesbaden. https://www.desta tis.de. Accessed 28 Jan 2020

Dierschke H, Briemle G (2008) Kulturgrasland: Wiesen Weiden und verwandte Staudenfluren. Ulmer, Stuttgart

Drusch M et al (2012) Sentinel-2: ESA's optical high-resolution mission for GMES operational services. Remote Sens Environ 120:25-36. https://doi.org/10.1016/j.rse.2011.11.026

European Space Agency (2017) Sentinel-2 spectral response functions. https://earth.esa.int/web/sentinel/user-guides/senti nel-2-msi/document-library/-/asset_publisher/Wk0TKajiIS $\mathrm{aR} /$ content/sentinel-2a-spectral-responses?redirect $=\mathrm{https}$ $\% 3 \mathrm{~A} \% 2 \mathrm{~F} \% 2 \mathrm{Fearth}$.esa.int $\% 2 \mathrm{Fweb} \% 2 \mathrm{Fsentinel} \% 2$ Fuser-guide s\%2Fsentinel-2-msi\%2Fdocument-library\%3Fp_p_id\%3D101 _INSTANCE_Wk0TKajiISaR\%26p_p_lifecycle\%3D0\%26p_p_ state \%3Dnormal\%26p_p_mode\%3Dview\%26p_p_col_ id\%3Dcolumn-1\%26p_p_col_count\%3D1. Accessed 26 Jan 2020

Friedl M, Schimel D, Michaelsen J, Davis F, Walker H (1994) Estimating grassland biomass and leaf area index using ground and satellite data. Int J Remote Sens 15:1401-1420

Gao J (2006) Quantification of grassland properties: how it can benefit from geoinformatic technologies? Int J Remote Sens 27:13511365. https://doi.org/10.1080/01431160500474357

Hank T, Bach H, Spannraft K, Friese M, Frank T, Mauser W (2012) Improving the process-based simulation of growth heterogeneities in agricultural stands through assimilation of earth observation data. In: 2012 IEEE international geoscience and remote sensing symposium. IEEE, pp 1006-1009

Hank TB, Bach H, Mauser W (2015) Using a remote sensing-supported hydro-agroecological model for field-scale simulation of heterogeneous crop growth and yield: application for wheat in central Europe. Remote Sens 7:3934-3965

Havelland L (2018) Jahresbericht 2018. Amt für Landwirtschaft, Veterinär- und Lebensmittelüberwachung, DE

Herrmann A, Kelm M, Kornher A, Taube F (2005) Performance of grassland under different cutting regimes as affected by sward composition, nitrogen input, soil conditions and weather-a simulation study. Eur J Agron 22:141-158. https://doi.org/10.1016/j. eja.2004.02.002

Jacquemoud S, Baret F (1990) PROSPECT: a model of leaf optical properties spectra. Remote Sens Environ 34:75-91

Liaw A, Wiener M (2002) Classifiaction and regression by random forest. R News 2:18-22

Löpmeier F-J (1983) Agrarmeteorologisches Modell zur Berechnung der aktuellen Verdunstung (AMBAV). Dt. Wetterdienst, Zentrale Agrarmeteorologische Forschungsstelle Braunschweig

Muir JS, Schmidt M, Tindall D, Trevithick R (2011) Field measurement of fractional ground cover: a technical handbook supporting ground cover monitoring for Australia. Canberra, Australia

Nendel C (2014) MONICA: a simulation model for nitrogen and carbon dynamics in agro-ecosystems. In: Mueller L, Saparov A, Lischeid G (eds) Novel measurement and assessment tools for monitoring and management of land and water resources in 
agricultural landscapes of Central Asia. Springer International Publishing, Cham, pp 389-405. https://doi.org/10.1007/978-3319-01017-5_23

Niggemann F, Appel F, Bach H, de la Mar J, Schirpke B (2014) The use of cloud computing resources for processing of big data from space for operational land surface monitoring in Germany. Paper presented at the Proceedings of the 2014 conferecnce on big data from space (BiDS'14), Frascati, Italy

Niggemann F et al (2015) Heterogeneous access and processing of EO-data on a cloud based infrastructure delivering operational products. Int Arch Photogramm Remote Sens Spat Inf Sci 40:663

Obermeier WA et al (2019) Grassland ecosystem services in a changing environment: the potential of hyperspectral monitoring. Remote Sens Environ 232:111273. https://doi.org/10.1016/j. rse.2019.111273

Punalekar SM, Verhoef A, Quaife TL, Humphries D, Bermingham L, Reynolds CK (2018) Application of Sentinel-2A data for pasture biomass monitoring using a physically based radiative transfer model. Remote Sens Environ 218:207-220. https://doi. org/10.1016/j.rse.2018.09.028

Quan X, He B, Yebra M, Yin C, Liao Z, Zhang X, Li X (2017) A radiative transfer model-based method for the estimation of grassland aboveground biomass. Int J Appl Earth Obs Geoinf 54:159-168. https://doi.org/10.1016/j.jag.2016.10.002

R Core Team (2018) R: A language and environment for statistical computing. R Foundation for Statistical Computing, Vienna, Austria. https://www.R-project.org/

Rayburn E, Lozier J (2003) A falling plate meter for estimating pasture forage mass. West Virginia University Extension Service

Sala OE, Paruelo JM (1997) Ecosystem services in grasslands. In: Daily GC (ed) Nature's services: societal dependence on natural ecosystems. Island Press, Washington, DC, pp 237-251

Schellberg J, Verbruggen E (2014) Frontiers and perspectives on research strategies in grassland technology. Crop Pasture Sci 65:508-523. https://doi.org/10.1071/CP13429

Schellberg J, Hill MJ, Gerhards R, Rothmund M, Braun M (2008) Precision agriculture on grassland: applications, perspectives and constraints. Eur J Agron 29:59-71. https://doi.org/10.1016/j. eja.2008.05.005

Schindler U, Steidl J, Müller L, Eulenstein F, Thiere J (2007) Drought risk to agricultural land in Northeast and Central Germany. J Plant Nutr Soil Sci 170:357-362. https://doi.org/10.1002/jpln.20062 2045

Smit HJ, Metzger MJ, Ewert F (2008) Spatial distribution of grassland productivity and land use in Europe. Agric Syst 98:208-219. https ://doi.org/10.1016/j.agsy.2008.07.004

Verhoef W (1985) Earth observation modeling based on layer scattering matrices. Remote Sens Environ 17:165-178

Verhoef W (1998) Theory of radiative transfer models applied in optical remote sensing of vegetation canopies. Wageningen Agrictultural University

Verhoef W, Bach H (2003) Simulation of hyperspectral and directional radiance images using coupled biophysical and atmospheric radiative transfer models. Remote Sens Environ 87:23-41

Verhoef W, Bach H (2007) Coupled soil-leaf-canopy and atmosphere radiative transfer modeling to simulate hyperspectral multiangular surface reflectance and TOA radiance data. Remote Sens Environ 109:166-182

Wachendorf M, Fricke T, Möckel T (2018) Remote sensing as a tool to assess botanical composition, structure, quantity and quality of temperate grasslands. Grass Forage Sci 73:1-14. https://doi. org/10.1111/gfs.12312

Wang J, Xiao X, Bajgain R, Starks P, Steiner J, Doughty RB, Chang Q (2019) Estimating leaf area index and aboveground biomass of grazing pastures using Sentinel-1, Sentinel-2 and Landsat images. ISPRS J Photogramm Remote Sens 154:189-201. https://doi. org/10.1016/j.isprsjprs.2019.06.007

ZALF (2020) Wetterstation Paulinenaue. Leibniz-Zentrum für Agrarlandschaftsforschung (ZALF) e. V., unpublished

Zhao Y, Liu Z, Wu J (2020) Grassland ecosystem services: a systematic review of research advances and future directions. Landscape Ecology 35:793-814. https://doi.org/10.1007/s10980-020-00980 $-3$ 